\title{
La Prenda
}

\author{
Por el Doctor JORGE AVENDAÑO V. (*)
}

\section{LAS GARANTIAS}

En toda obligación con efectos jurídicos, el acreedor tiene, respecto de los bienes que integran el patrimonio de su deudor, el derecho de reali, zarlos y hacerse pago con su importe, en caso de incumplimiento.

A esta afectación genérica de todos los bienes del deudor, existentes al momento de la ejecución, se ha dado en llamarla "prenda general". Con esta denominación imperfecta se pretende destacar que dichos bienes del patrimonio del deudor, están implícitamente afectados al cumplimiento de sus cbligaciones de tipo patrimonial o mixto. Al decir "implícitamente" hago referencia a la circunstancia de que no se precisa afectación expresa; es decir, no es menester la declaración del deudor de que grava los bienes de su patrimonio en garantía de las obligaciones contraídas: ese gravamen existe por mandato del derecho.

El grado en que está garantizado el acreedor, es decir las posibilidades con que cuenta de hacer efectivo su crédito, resulta así en razón directa de la riqueza del patrimonio de su deudor. Si al momento de producirse la ejecución por incumplimiento, el deudor es titular de bienes que exceden de sus obligaciones, lo más probable es que el acreedor pueda hacer efectivo su crédito. Si, por el contrario, el deudor carece de bienes, ya sea porque nunca existieron o porque ha dispuesto de ellos, o si a pesar de haber bienes existen también deudas que alcanzan o superan el activo, es casi seguro que el acreedor no podró hacer efectivo su crédito.

Con el fin de obviar este riesgo, desde antaño existen las garantías especificas, que son seguridades concretas que el deudor otorga en favor de su acreedor, de modo que éste pueda hacer efectivo su crédito con cargo a ellas, sin estar sujeto a la eventualidad de la insolvencia de su deudor. Estas garantías han adoptado, principalmente, las formas siguientes:

a) garantías personales; $y$

b) garantías reales.

(*) Catedrático Titular de Derecho Civil y Decano de la Facultad de Derecho de la Ponuficia Universidad Católica. 
a) Sin perjuicio del gravamen genérico de los bienes de su patrimonio, el deudor puede afectar otro $u$ otros patrimonios en garantía de la obligación contraída. Esto significa que además del deudor directo, están obligadas otras personas, cuyos patrimonios resultan así también comprometidos (1). Estos otros obligados no son deudores directos del acreedor en cuanto que la causa de su obligación no es la misma que ha dado lugar al crédito principal. Resultan más bien originariamente ligados con el deudor, quien solicita su concurso para que se "asocien" a él y lo garanticen frente al acreedor. Este cuenta entonces, a efecto de lograr la prestación, no solamente con el patrimonio de su deudor directo, sino además con el del otro $u$ otros obligados, los cuales tienen la calidad de fiadores.

El vínculo que liga a los fiadores con el acreedor es de tipo contractual, y es aquel "en virtud del cual un tercero llamado fiador promete a un acreedor pagarle su deuda si el deudor no ejecuta su obligación" (2).

El fiador puede estar obligado frente al acreedor de modo simple o de modo solidario. En el primero de esos casos el fiador queda obligado a satisfacer la obligación solamente en defecto del deudor, o sea si éste incumple: lo cual supone, necesariamente, que la ejecución se dirija en primer término contra el deudor directo. Si ella resulta infructuosa, el acreedor puede dirigirla contra el fiador.

En la segunda clase de fianza, esto es la solidaria, el fiador queda obligado conjuntamente con el deudor. Este efecto no es propio de la fianza, la cual supone excusión previa de los bienes del deudor, sino de la solidaridad pasiva, que es un carácter de que pueden estar investidas las obligaciones en general y que consiste en la concurrencia de varios deudores, cada uno obligado a cumplir toda la deuda (3). De modo que al acreedor puede exigir indistintamente al deudor directo o a los fiadores el cumplimiento íntegro de la obligación, lo cual significa pluralidad de oblizados, en el mismo grado y cada uno por el íntegro de la prestación.

La fianza solidaria es ciertamente una mayor garantía para el acreedor que la fianza simple, ya que está eximido de accionar necesariamente en primer término contra su deudor directo.

Son varias las ventajas y desventajas de esta garantía personal denominada fianza. Entre las primeras podemos consignar que el acreedor cuenta no solamente con el patrimonio de su deudor (como ocurriría en caso de que la obligación no estuviera garantizada), sino que puede hacer efectivo su crédito también contra los bienes de los fiadores. Existe, pues, pluralidad también de patrimonios genéricamente afectados. El riesgo de la

(1) Si se acepta la teoría personalista, sustentada por Aubry y Rau, no es el patrimonio la garantía genérica del acreedor sino los bienes que lo integran. Resultaría así imperfecto referirse a la afectación del patrimonio; debe decirse que están afectos los bienes del patrimonio del deudor. Sin embargo, hecha esta aclaración y para simplificar, en adelante hablaremos de la afectación del patrimonio.

(2) Colin y Capitant: "Curso elemental de derecho civil". Tomo V. Garantías personales y reales. Editorial Reus S.A.. Madrid, 1925.

(3) Castañeda, Jorge Eugenio: "Instituciones de Derecho Civil". Lima, 1957. 
insolvencia está diluido porque en todo caso existen otros patrimonios compromeidos. Pero no ha desaparecido del todo porque esa misma insolvencia puede llegar a afectar $\alpha$ los fiadores. Es ésta, precisamente, la desventaja más saltante de la garantía personal. La seguridad no es total porque no se puede descartar, así existan numerosos obligados, la posibilidad de que tocios ellos devenguen insolventes. Es cierto que el acreedor tiene medios indirectos para preservar el patrimonio de su deudor y fiadores, tales como la acción revocatoria y la oblícua, pero no puede intervenir de modo directo en los actos y actividades de sus obligados. La amenaza de la insolvencia es, pues, una posibilidad que no puede descartarse.

b) Esa amenaza desaparece cuando existe una garantía real, que consiste en la afectación expresa que se hace de un bien o varios bienes al cumplimiento de una obligación. El bien afectado, que generalmente es de propiedad del deudor, queda así marcado o destinado a que con su importe se haga pago el acreedor en caso de incumplimiento de su deudor. Para aquel ya no tiene importancia que este último sea solvente o no, porque su garantía no está constituída por el total del patrimonio, sino de modo preferente por el bien afectado. Por esto, se habla de garantía real, en el sentido de que es la cosa la que garantiza. Gráficamente, podría decirse que la deuda no la soporta ya una persona (el deudor), sino en realidad una cosa (la gravada con la garantía). La expresión vale solamente por su contenido didáctico y no es totalmente exacta porque el sujeto pasivo de una obligación es siempre una persona y jamás una cosa, y además porque la responsabilidad personal del deudor no desaparece por razón de la garantía. Así, si la garantía deviniera insuficiente, o si se destruyera el bien afectado, el acreedor conserva siempre el derecho de exigir al deudor el íntegro o el saldo de la abligación, y hacerlo efectivo con cargo a su patrimonio, conforme a las reglas de las obligaciones simples. Pero la expresión de que la deuda la soporta una cosa es elocuente porque revela de qué modo esa cosa está destinada a que el acreedor haga efectivo su crédito.

El derecho que surge en el acreedor respecto de esa cosa qiena que ha sido afectada en su favor en garantía del cumplimiento de la obligación. es de naturaleza real, con las notas o atributos propios de todo derecho real, esto es las facultades de persecución y de preferencia.

Sabido es que el derecho real absoluto es la propiedad. Ella reúne todos los atributos, confiere a su titular todas las facultades. En rigor podría decirse que no existen derechos reales sino derecho real, y que éste es la propiedad. Todos los demás derechos reales no serían sino partes del derecho real pleno, y por ello derechos reales también, aunque parciales o restringidos. Esta es, precisamente, la naturaleza de las desmembraciones de la propiedad, o derechos reales menores (usufructo, uso, habitación, e inclusive la posesión, que es el contenido de la propiedad, y las servidumbres, que son restricciones del dominio que se erigen bajo la forma de derechos reales para su titular).

¿Y los derechos reales de garantía? ¿Son también desmembraciones del dominio? ¿Acaso confieren a su titular las facultades que constituyen otributos del dominio, es decir derecho a usar o disfrutar? ¿Ácaso imponen 
al propietario una restricción de sus facultades, en la misma medida en que confieren derechos al acreedor?

En verdad, no son desmembraciones del dominio. El derecho de propiedad, cuando la cosa está gravada con un derecho real de garantía, se mantiene prácticamente incólume; y el acreedor, salvo casos, no tiene facultades de uso o disfrute de la cosa. Son derechos limitados y limitativos que no constituyen desmembraciones de la propiedad.

Son limitcdos porque "su contenido es ciertamente menor que el de la propiedad. No atribuyen al titular el derecho a la realización del valor, porque ello es derecho general, anterior, sobre todo el patrimonio. Lo que hacen es concretar sobre ciertos bienes ese derecho de agresión del acreedor. Al concretar, completan el derecho con las notas de la persecusión $Y$ la preferencio. Es un poder directo. El derecho se transforma de relativo en absoluto" (4).

Son Intilativos en cuanto restan determinadas facultades al propietario. Cuando se trata de aquellos derechos reales en los que se precisa el desplazamiento o entrega del bien al acreedor o a un tercero que lo guarào, el deudor está privado de la posesión, lo cual significa una limitación importante. Sin perjuicio de lo anterior, en todos los derechos reales de garantía el acreedor no puede realizar actos de disposición material o jurídica que disminuyan el valor del bien afectado, lo cual es evidentemente otra restricción del dominio.

Las ventajas que representan estas garantias reales respecto de las personales, son obvias. "Con ellas no hay que temer ni las enajenaciones (disminución del patrimonio del deudor), ni las deudas nuevas (aumento del pasivo): armado de un derecho real embargará (el acreedor) el bien ofectado al pago de sus derechos, encuéntrense donde se encuentre, y siempre que el valor de ese bien sea por lo menos igual al monto de su crédito, tendrá la certeza de ser pagado, armado como está del derecho de reclamación y del derecho de preferencia. Por esta razón... Loysel estimaba que mientras "fiador litiga, prenda paga": el caucionero (entiéndase el fiador; embrolla, el bien comprometido paga. Un obligado puede fallecer o hacerse insolvente o mostrarse recalcitrante; la cosa comprometida permanece ella misma, inmutablemente, dispuesta a cumplir lo que de ella se esperaba".

"Con una condición, sin embargo, esto es que las garantías reales estén organizadas en modo satisfactorio; $y$ fué precisamente por razón de su defectuosa organización en Roma por lo que las garantías personales conservaron en el derecho romano una gran importancia, aún después de la introducción de la hipoteca. En nuestra época están relegadas a segundo plano; en Alemania se les ha asignado el carácter de ser de segundo orden (art. 232 del Código Alemán): las cosas son más seguras que los hombres" (5).

(4) Ferrandis Vilella: "Introducción al estudio de los derechos reales de garantía". Anuario de Derecho Civil, Madrid, Enero 1954. Enero-Marzo No 1. pág. 37.

(5) Josserand, Louis: "Derecho Civil". Ediciones Jurídicas Europa-Ámérica, Bosch y Cía. Editores Buenos Aires. Tomo II, vol. 2, pág. 396. 
Las garantías reales han sufrido una evolución que no responde necesariamente a un criterio cronológico.

En las legislaciones poco avanzadas, es el derecho de propiedad el utilizado. Fn garantía de la obligación, el deudor transfiere a su acreedor la propiedad de un bien, conviniendo que vuelva a serle transferido cuando se produzca el cumplimiento. Es el procedimiento conocido como enajenación fiduciaria, que constituye una garantía plena para el acreedor porque adquiere el dominio de un bien, y lo conserva en caso de incumplimiento; pero presenta el inconveniente de poner al deudor a merced de su acreedor, al punto de que una vez cumplida la obligación, cuenta tan sólo con una acción de tipo personal para exigir la restitución. Carece. pues, de acción real.

Más adelante se idea el procedimiento de transferir solamente la posesión de un bien al acreedor, no ya la propiedad. El deudor sigue siendo propietario y por consiguiente conserva la acción reivindicatoria para recuperar la posesión del bien una vez cumplida la obligación. El acreedor no puede usar del bien, salvo autorización expresa. Simplemente lo retiene, en nombre de su deudor, a efecto de hacerse pago con su importe en caso de incumplimienio. Aquí existe ya constitución de garantía.

Hay evidentemente superioridad de esta seguridad respacto de la encjenación fiduciaria, pero existen siempre inconvenientes. Ásí, se priva al deudor de la posesión, por consiguiente del uso y disfrute del bien afectado; $y$, por otra parte, se impone al acreedor las obligaciones que resultan de la custodia de la cosa ajena, ya que por su calidad de depositario. sufre la responsabilidad de la pérdida o detrimento ocurridos por su culpa.

Fué preciso, en estas circunstancias, concebir una garantía más sutil Y que superara las deficiencias de la anterior. Surge así la hipoteca, que es la garantía real más perfeccionada y que consiste en la áfectación que hace el deudor da un bien de su propiedad, cuya posesión conserva. El acreedor tiene los derechos de persecución y de preferencia. Por el primero, puede reclamar la cosa a quien la tenga, una vez producido el incumplimiento, a fin de hacerse pago con su importe; por el segundo, tiene el derecho de cobrar su crédito antes que otros acreedores de ese mismo deudor. Como el bien permanece en poder del deudor, este tipo de garantía supone, como es evidente, un sistema de publicidad adecuádo que permita a los terceros conocer que la afectación existe; y. por otra parte, ella puede recaer únicamente respecto de bienes que puedan ser indubitablemente identificados. La persecusión es así una realidad y no simple ilusión.

"A pesar de su abrumadora superioridad, nos ilustra Josserand, la hipoteca no suplanta nunca a la prenda. Tiene sus defectos $y$ sus ventajas. La hipoteca, perfecta para los bienes que, no sujetos a perecer, admiten una identificación fácil, es de aplicación menos cómoda a los bienes susceptibles de desaparición y también a aquellos cuya identificación es difícil: en cuanto a los primeros el acreedor hipotecario tiene que temer su destrucción, su disimulación, la ocultación; para los otros, los terceros tendrán que temer sorpresas desagradables, porque no se podrá fácilmente 
avisarles de la existencia de las hipotecas" (6).

Hemos dicho anteriormente que esta evolución de las garantías reales no se produjo en forma rigurosamente cronológica. En efecto, aún hoy es posible encontrar comunidades de bajo nivel jurídico en las que todavía se utiiza la enajenación fiduciaria. Sin ir muy lejos, en algunos lugares de la sierra peruana, ese procedimiento es el más empleado.

Las garantías reales adoptan distintas formas $y$ así cada una de ellas recibe una denominación diferente. Ellas son la prenda, la hipoteca y la anticresis. El derecho de retención, incluído en nuestra legislación como derecho real de gorantía, no lo es en verdad. Carece su titular de las facultades plenas de persecusión y preferencia. Constituye una forma o modalidad de la compensación (7).

Las notas principales de las tres garantías reales citadas, son las siguientes:

Prenda.-Recae sobre bienes muebles y supone desplazamiento, es decir entrega real de la cosa gravada. La entrega se hace por el deudor - por un tercero, originariamente ajeno a la obligación, que en el derecho francés se llama "caucionero real" Y que entre nosotros podría calificarse como "fiador prendario", si cabe. La entrega se hace al acreedor o a un tercero, los cuales guardon la cosa en nombre del deudor.

Hipoteca.-Recae sobre bienes inmuebles y no hay entrega del bien, el cual queda en poder del deudor, quien lo usa y disfruta. En las legislaciones de más avanzada organización hipotecaria, es requisito constitutivo del derecho que sea inscrito en el registro que al efecto existe, es decir que goce de publicidad.

Anticresis.-Recae sobre un bien inmueble, el cual es entregado al acreedor a fin de que éste lo explote y aplique los frutos al pago de los intereses y capital adeudados, en este orden. Es una seguridad real muy poco usada, susceptible de garantizar únicamente un préstamo de dinero.

Las notas o características de la prenda y la hipoteca no se han conservado tan claras a través del tiempo; ni lo son hoy, en que se legisla sobre la "prenda sin desplazamiento" y sobre la "hipoteca mobiliaria". Esto quiere decir que el requisito de la entrega no sería más de la esencia de la prenda; y que tampoco lo sería de la hipoteca el que necesariamente recaiga sobre bienes inmuebles.

Antes de concluir con esta exposición general de las garantías, conviene distinguir las reales de los privilegios. Conforme al artículo 2095 del Código Civil francés, el privilegio es "el derecho que la calidad del crédito da a un acreedor, en virtud de la ley, para ser preferido a los demás acreedores, aún hipotecarios". Se trata de preferencias que la ley establece en atención a la calidad del crédito (así, beneficios sociales, pensiones de alimentos, impuestos en favor del Fisco). Las notas o caracteres que se atribuyen a los privilegios, que permiten diferenciarlos de las garantías reales, son las siguientes:

1) Mientras que las garantías reales son generalmente convencio-

(6) Josserand, Louis. - op. cit. pág. 433.

(7) Léase Josserand.- op. cit.. pág. 400 y ss. 
nales (nacen por voluntad de las partes), los privilegios son siempre legales;

2) Las seguridades reales recaen sobre bienes específicamente determinados (principio de la especialidad, que veremos más adelante); los privilegios versan sobre bienes muebles e inmuebles, generalmente como conjunto:

3) En caso de concurrencia entre acreedores privilegiados $y$ acreedores prendarios e hipotecarios, tienen preferencia los primeros; $Y$

4) En caso de conflicto entre diversos acreedores privilegiados, la preferencia no se regula de acuerdo a las fechas de los créditos, sino atendiendo a su calidad.

En nuestro pás, el Código Civil no se ocupa de los privilegios. Ellos se encuentran establecidos en leyes especiales, principalmente en la $\mathrm{N}$ \% 7566 (Ley Procesal de Quiebras), arts. 110 y 111.

\section{LA PRENDA CIVIL}

Sumario.-La institución ha de ser tratada en cinco partes: noción, caracteres, requisitos, efectos y finalmente extinción. A continuación nos ocuparemos de la prenda de créditos y acciones, de la prenda de dinero, que se discute en doctrina, y por último de la llamada prenda tácita.

1.-NOCION.-Se asignan tres acepciones a la palabra prenda. Constituye, en primer término, el contrato en virtud del cual el deudor de una obligación, o un tercero, entrega una cosa mueble de su propiedad al acreedor $\odot$ a un tercero, en garantía del cumplimiento de la obligación. Este contrato de prenda es paralelo al contrato o vínculo obligacional que se garantiza. Por consiguiente, supone un acuerdo de voluntades distinto del que da lugar a la obligación garantizada; si bien ambos se producen generalmente en el mismo momento y están vinculados. Es importante destacar que se trata de dos convenciones diferentes, porque puede ocurrir que una de ellas sea nula o anulable mientras que la otra sea válida. Más adelante, a propósito del carácter de derecho accesorio que tiene la pren$\mathrm{da}$, veremos en qué forma influye la invalidez de un contrato en el otro.

Por prenda debemos entender también la cosa que se entrega en garantía de la obligación. Asi, se dice que el acreedor tiene derecho a pedir el remate de la prenda, es decir del objeto que fué afectado en su favor.

Finalmente, se designa con el nombre prenda el derecho real que surge en el acreedor respecto de la cosa (prenda) como consecuencia del contrato de prenda celebrado.

En el Código Civil peruano se atribuye a la prenda esta última acepción, y por esta razón se encuentra legislada en el Libro de los Derechos Reales (arts. 981 a 1003). Sin embargo, hay algunas disposiciones de ese Código que se refieren al contrato de prenda (p. ej. la primera parte del 985); $y$ otras que utilizan el vocablo como sinónimo de la cosa afectada (así, los arts. 982, segunda parte del 985 y 986, entre otros).

El Código anterior, de 1852, dió preferencia a la noción contractual de la prenda, y por esto la legisló entre los contratos. Lo mismo debe de- 
cirse del Código de Comercio vigente, el cual incluye la prenda mercantil entre los contratos de comercio.

A lo largo de este trabajo vamos a examinar el derecho real de prenda, no así su aspecto contractual. Este será tratado marginalmente y sólo en cuanto sea preciso para desarrollar el aspecto real.

2.-CARACTERES.-Se distinguen los siguientes: a) la prenda es accesoria, b) es mobiliaria, c) es indivisible. Además, y finalmente, d) goza del carácter llamado de la especialidad.

a) Derecho accesorio. - No se concibe la prenda sino como accesoria de una obligación. Esta es una nota propia de todos los derechos reales de garantía. Sin embargo, en el derecho alemán y en el suizo, se admiten las llamadas "deuda territorial" Y "cédula hipotecaria", respectivamente, que son títulos que se otorgan al portador o a la orden y que el propietario del inmueble puede utilizar luego para garantizar cualquier crédito. La garantía se constituye, pues, primero, en forma autónoma sin que garantice obligación alguna. Esta noción de la garantía como derecho autónomo es moderna, de origen germano, y se aplica únicamente a la hipoteca. La prenda civil, en cambio, mantiene su carácter de derecho accesorio, esto es de ser constituída siempre en seguridad de un crédito (art. 981 inc. 2).

El carácter accesorio de la prenda da lugar a diversas consecuencias prácticas:

1) La prenda sigue la condición jurídica del crédito que garantiza. Por consiguiente, por ejemplo, si el crédito es un bien ganancial, la prenda también lo es.

2) La prenda se extingue por el pago y en general por todos los demás modos de extinción de las obligaciones (lo cual quiere decir que la vida de la prenda depende de la vigencia de la obligación que ella está garantizando).

3) Como consecuencia de lo anterior, y por lo mismo que es un derecho accesorio, la prenda no puede existir sin el soporte de una obligación principal a la cual garantiza. En consecuencia, la nulidad de ésta entraña la nulidad de aquella. Lo opuesto no ocurre, es decir la nulidad de la prenda no acarrea la invalidez de la obligación, ya que ésta, por ser autónoma, tiene vida propia.

En cuanto a las obligaciones que pueden ser garantizadas con prenda, la ley no se pronuncia. Se admite que cualesquiera obligación puede serlo: las simples y también las modales, es decir las sujetas a condición -ya sea suspensiva o resolutoria-, a plazo y con cargo o modo.

b) Derecho mobiliario. - La prenda recae sobre los bienes muebles. Como se sabe, el criterio para distinguir entre nosotros un bien mueble de un inmueble, no es el de la movilidad, como fué conforme al Código anterior, sino que es de tipo legal. Es la ley la que, por razones de tipo económico, ha hecho una enumeración de los bienes inmuebles (art. 812) y de los muebles (art. 819). Se ha respetado en parte el criterio de la movilidad (art. 819, inc. 1), pero no de modo absoluto.

Pueden darse en prenda toda clase de bienes muebles, con dos con- 
diciones: que sean susceptibles de entrega $y$ que puedan ser vendidos o enajenados. Lo primero se justifica porque, como ya se ha dicho y se verá después más extensamente, la prenda supone entrega del bien gravado; y lo segundo se explica porque la prenda debe ser subastada en caso de incumplimiento, a fin de que el acreedor satisfaga su crédito con el importe de la venta.

En cuanto a los bienes muebles incorporales (derechos, créditos), ellos pueden ser dados en prenda siempre que consten de algún título cierto (8), el cual debe ser entregado al acreedor o al tercero conforme a las reglas que existen para la tradición de derechos (art. 846).

Es indispensable que los bienes muebles que se dan en prenda sean existentes $y$ debidamente individualizados. Se descarta, por consiguiente, la posibilidad de que se afecten con prenda los bienes futuros, si bien respecto de ellos cabe la llamada promesa de prenda, que ciertamente no constituye un derecho real.

c) Derecho indivisible.-Este carácter de la indivisibilidad de la garantía, tiene tres aspectos:

1) L La prenda dura por entero para garantizar el crédito entero, mientras no sea totalmente extinguida la deuda y aún cuando ésta sea divisible. Así por ejemplo, si el heredero de un deudor pagara su parte de la obligación de su causante, no podría pretender la restitución de la prenda si es que los demás herederos no han pagado también.

2)-La prenda afecta el bien en todas sus partes; de modo que si fuera dividido (material o jurídicamente), cada parte, o cada uno de los bienes dados en prenda (si son más de uno), está afectado de la garantía por el crédito entero.

3)-Finalmente, la indivisibilidad debe enterderse también como que la prenda garantiza el crédito entero, incluídos intereses, gastos, etc.

d) Especialidad de la prenda.- En el derecho antiguo, tanto la prenda como la hipoteca podían recaer no sólo sobre un bien determinado, sino sobre todas las cosas que formaban el patrimonio de una persona. Assí, se decía que la afectación legal en favor del propietario de los muebles introducidos por el arrendatario en el inmueble materia de locación, era de naturaleza prendaria; y a esto se debe la denominación que criticamos al comienzo de este trabajo, de "prenda genérica de los bienes del deudor" para significar la garantía legal que todo acreedor tiene representada por el patrimonio de su deudor.

Modernamente, tanto la hipoteca como la prenda -en especial aquella porque el carácter surge con mayor nitidez- gozan de la especialidad, la cual adopta dos formas: especialidad en cuanto al bien afectado $y$ especialidad en cuanto al crédito. Por la primera debe entenderse que la prenda sólo puede recaer sobre un bien mueble individualizado y determinado; por la segunda que la prenda debe constituirse en garantía de un crédito también concretamente determinado.

(8) El término "título" está utilizado acá como sinónimo de documento, que es una de sus acepciones válidas. La otra es la de acto jurídico, y así se lo entiende cuando se habla de "justo título" en materia de prescripción adquisitiva. 
En otros términos, este principio de la especialidad atenta contra la indeterminación del bien afectado $y$ del crédito que se garantiza.

3.-REQUISITOS.-Los artículos 981 y 983 del Código Civil enumeran los cuatro requisitos de la prenda. Los tres primeros, consignados en el artículo 981, son de la esencia de la prenda: si faltara alguno de ellos, no se habría constituído el derecho real de prenda. En cambio, la exigencia contenida en el artículo 983 no es de la esencia de la prenda sino solamente a fin de que ella tenga efectos contra terceros.

Los requisitos esenciales de la prenda son los siguientes: a) que se entregue el bien al acreedor o a la persona que deba guardarlo; b) que la prenda asegure el cumplimiento de una obligación, aún cuando ésta se haya contraído sin la intervención de quien constituyó la garantía; y c) que afecte el bien quien sea su dueño $y$ tenga su libre disposición, 0 , en otro caso, quien esté autorizado legalmente.

El cuarto y último requisito, que se exige para que la prenda surta efecto contra terceros, es que conste por escrito de fecha cierta.

Examinemos cada uno de estos requisitos separadamente.

a) Entrega o desplazamiento de la prenda. La justificación de esta exigencia es doble: la entrega de la prenda constituye una forma de dar publicidad al gravámen, es decir un medio de hacer saber a los terceros que la cosa está afectada al pago de una obligación; y constituye, además, una garantía para el acreedor porque si la prenda quedara en poder del deudor, estaría expuesta a que éste la enajenara, sin posibilidad de ejercer acción real alguna contra los adquirentes de buena fé.

El profesor Messineo nos explica este requisito en los términos siguientes: "La función de la desposesión está en hacer imposible de hecho que el deudor pueda, después de la constitución de bien dado en prenda, enajenarlo a otro sujeto; lo que sería cómodo, con toda facilidad, si el deudor tuviese la posesión de lo cosa" (9).

¿Quién hace entrega? $\mathrm{E}$ que constituye la garantía, que ha de ser propietario de la cosa gravada, conforme veremos más adelante. Generalmente se trata del mismo deudor. Sin émbargo, puede también constituir la garantía un tercero, es decir una persona distinta del deudor. No se trata, en verdad, de un fiador, ya que no compromete su patrimonio. Es, simplemente, un tercero que entrega un bien de su propiedad que es afectado con prenda en garantía de una obligación que no es suya (10).

$i \bar{A}$ quién se hace la entrega? Generalmente al acreedor. Sin embargo, se permite también de modo unánime que la entrega se haga a un tercero. El Código Civil peruano admite expresamente esta entrega al tercero en el inc. 1 del art. 981 y en el segundo párrafo del art. 985. En realidad, lo que interesa no es que la cosa sea entregada necesariamente al acreedor; lo importante es que el constituyente de la prenda se despoje de ella.

(9) Messineo, Francesco: "Manual de Derecho Civil y Comercial". Tomo IV. Derecho de las Obligaciones. Ediciones Jurídicas Europa-América, Buenos Aires, 1955. pág. 85.

(10) En el derecho francés este tercero es llamado "caucionero real". 
En cuanto a la forma de entrega, no hay acuerdo unánime en la doctrina. En el derecho peruano, en cambio, el problema no admite discusión.

La mayoría de los autores exigen que la entrega sea efectiva, es decir que se produzca una tradición real, lo cual supone entrega material de la cosa. Algunos tratadistas creen, por el contrario, que bastaría la tradición ficta, esto es la que se entiende realizada (ver art. 845 C.C.). Como se sabe, en la tradición ficta ocurre un cambio de título posesorio. En este caso el deudor, que viene poseyendo a título de propietario, cambiaria simplemente su calidad posesoria por la de depositario, guardando la cosa en nombre de su acreedor. Objetamos esta fórmula con los argumentos de seguridad $y$ difusión antes enunciados. Discrepamos, así mismo, de una tercera posición que defiende Lafaille en los términos siguientes: "No hay ningún impedimento para que las partes de común acuerdo, celebrado ya el contrato de prenda, establezcan que la cosa vuelve a poder del deudor, evitándose de este modo los males económicos antes señalados. Tal estipulación ha de ser expresa, pues, devolviendo lisa y llanamente la garantía. se renuncia tácitamente a ella" (11).

Es cierto que la entrega efectiva de la cosa presenta inconvenientes serios en el orden económico. Empero, también es cierto que de la fórmula sugerida por Lafaille, que consiste en que mediante pacto recupere el deudor la tenencia de la cosa, pueden derivarse serios perjuicios para el acreedor y para los terceras. Es inexplicable que Lafaille exija el requisito de la entrega inicial, con lo cual reconoce que ella cumple el doble rol de publicidad y garantía; y sin embargo admita que la prenda pueda ser luego devuelta, como si ya no hubiera razón para que siga cumpliendo esa doble finalidad.

En nuestro derecho no hay lugar a dudas: la entrega ha de ser material. Debe haber transferencia de la posesión de la cosa. Por virtud de la tradición, el acreedor o el tercero que recibe la prenda, se convierte en poseedor inmediato de ella (es decir poseedor temporal en virtud de un derecho, el de acreedor prendario) (Ver art. 825).

Si el acreedor devolviera la cosa al deudor, se extingue la prenda. Así lo dice expresamente la sequnda parte del artículo 985 del Código Civil. Se entiende que habría una renuncia tácita del derecho real. Ello tiene su explicación en que el acreedor no sería más poseedor de la prenda. ya que habría perdido el ejercicio de hecho de uno de los poderes inherentes a la propiedad (ver art. 824).

Como se ha dicho anteriormente, hay prenda no solamente de bienes corporales sino también de derechos. ¿Cómo ha de hacerse la entrega de esta clase de bienes? La solución está contenida en el artículo 982, que dispone que cuando la prenda consista en créditos o valores, deben cedersə o entregarse los titulos y notificarse al deudor. Esta última exigencia riqe solamente cuando sea indispensable la cesión del crédito (ver art. 1457 del C.C.); no así cuando se trate de títulos endosables o al portador, casos en los cuales bastará el endoso o la entrega, respectivamente.

(11) Lafaille, Héctor: "Derecho Civil", Tomo V, Tratado de los Derechos Reales, vol. III. Ediar Sociedad Anónima Editores. Buenos Aires, 1945, pág. 186. 
¿Qué ocurre si después de contraída la obligación principal y celebrado inclusive el contrato de prenda, el deudor no cumple con entregar la cosa? El primer efecto es que no surge el derecho real de prenda (segunda parte del art. 985). El segundo es de tipo obligacional: el acreedor puede exigir el cumplimiento de la obligación principal aunque el plazo no esté vencido (art. 991, concordante con el 1114 inc. 2).

Se plantea, finalmente, el problema de si subsiste el derecho real en caso de que pierda el acreedor la posesión de la cosa gravada. El caso no está resuelto de modo expreso en la legislación peruana. El art. 3208 del Código Civil argentino en cambio, dice: "Se juzga que el acreedor continúa en la posesión de la prenda, cuando la hubiese perdido o le hubiere sido robada, o la hubiera entregado $\alpha$ un tercero que se obligase a devolvérsela".

Examinemos estas tres posibilidades a la luz de la ley peruana.

En caso de pérdida de la cosa parece ser que se extingue la prenda, ya que conforme al artículo 848 la posesión termina "cuando se pierde el ejercicio de hecho a que se refiere el artículo 824", es decir el ejercicio de alguno de los poderes inherentes a la propiedad a que se refiere el ar. tículo 850 .

En caso de que la prenda haya sido robada al acreedor, creemos que no ha perdido la posesión $y$ tiene derecho a reivindicarla. El adquiriente de la cosa robada, aún cuando sea de buena fé, no está amparado por el art. 890 y sufre las consecuencias de la acción reivindicatoria.

Finalmente, si el acreedor ha entregado temporalmente la cosa a un tercero que se obliga a devolvérsela, por ejemplo a un depositario, es evidente que no ha perdido la posesión mediata de la cosa, ya que ese tercero, digamos el depositario, tendría la calidad de poseedor inmediato (o simple detentador conforme a legislaciones como la francesa y argentina). El derecho real de prenda debe pues subsistir.

Después volveremos más extensamente sobre este tema.

b) La prenda debe asegurar el cumplimiento de una obligación. Es éste el segundo requisito legal de la prenda. Ya comentamos esta exigencia cuando nos referimos a los caracteres del derecho real de prenda $y$ dijimos que es necesariamente accesorio de una obligación, es decir que carece de vida autónoma.

Este inciso segundo del artículo 981 contiene una parte final que resulta incomprensible. En realidad, en la edición oficial del Código se ha omitido la palabra "aún", que figuraba en el Proyecto y que mereció aprobación. El inciso debe leerse así: "Que la prenda asegure el cumplimiento de una obligación, aún cuando ésta se haya constituído sin la intervención de quien constituyó la garantía". La ley establece de modo expreso el carácter accesorio de la prenda. Esta accesoriedad existe no solamente cuando el constituyente de la prenda es el propio deudor, sino también cuando es un tercero.

c) La prenda debe ser constituída por el propietario de la cosa. Este tercer requisito de la prenda se justifica porque la afectación del bien constituye un acto de disposición del mismo, disposición que sólo corresponde al propietario conforme al artículo 850 del Código Civil. Debe tenerse presente que la afectación de la cosa importa la posibilidad de que 
luego sea enajenada por el acreedor, en caso de incumplimiento de la obligación principal. Esta eventual enajenación importa, sin lugar a dudas, un acto de disposición jurídica que compete solamente al dueño.

Este inciso del art. 981 materia de exámen, exige no solamente que el que constituye la garantía sea dueño de la cosa, sino además que tenga. su libre disposición. Esto es importante porque podría ocurrir, por ejemplo, que el propietario hubiera constituído un derecho de usufructo sobre el bien que pretende gravar, caso éste en el cual no tendría la libre disposición del mismo; o podría ser, también en vía de ejemplo, que el propietario fuera incopaz, caso en que tampoco gozaría de la libre disposición.

En la parte final del artículo, se autoriza a que constituya prenda "quien esté autorizado legalmente". Es éste el caso de un apoderado que entrega en prenda un bien de propiedad de su mandante. Es preciso, en este supuesto, que el mandato sea expreso. No bastaría un poder gensral. Sería indispensable un poder especial, que facultara al mandatario para gravar los bienes de su poderdante.

Tratándose de bienes muebles, puede ocurrir que el deudor entregue en prenda una cosa ajena. ¿Gozaría el acreedor en este caso del derecho real de prenda, con las consecuencias que de ello derivan, o estaría sujeto a la reivindicación que contra él interpusiera el verdadero dueño? La solución está dada por el artículo 1000, que ampara al acreedo: y lo faculta para retener la cosa que le fué entregada y pagarse con su vaior. Se exigen, $\sin$ embargo, determinados requisitos que pasamos a enumerar y comentar:

1.-El acreedor debe ser de buena fé, es decir creer en la legitimidad de su posesión (art. 832); lo cual significa que debe ignorar la circunstancia de que su deudor no era en verdad dueño de la cosa que entreá́ en prenda. Esta ignorancia del acreedor, ha de deberse a un error, el cual puede ser tanto de hecho como de derecho. El Código peruano, en este sentido, constituye prácticamente una excepcićn, ya que admite no sólo el error de hecho sino también el de derecho.

2.-El bien entregado en prenda no puede haber sido robado por el constituyente de la prenda a su verdadero dueño, ni puede haberlo perdido este último. En consecuencia, la posesión del constituyente de la prenda debe haber nacido de una entrega voluntaria que le hizo el verdadero dueño. Âsí, por ejemplo, si le dió la cosa en depósito o préstamo, y aquel, abusando de sus facultades de depositario o comodatario, la entregó en prenda a un tercero.

3.-La cosa no puede haber sido adquirida por el deudor en un establecimiento abierto al público en el que normalmente se expenden cosas de la clase de la entregada en prenda. La razón de ser de esta exigencia es la misma que explica el artículo 85 del Código de Comercio. Cuando las gentes acuden a un establecimiento comercial abierto al público, no tienen porqué indagar acerca de si el vendedor es o nó el verdadero dueño; se presume que lo es. $Y$ no puede ser de otro modo porque se traboría y dificultaría la venta en los establecimientos comerciales.

$\mathrm{Si}$ se dan los tres requisitos antes referidos, el acreedor que recibió en prenda una cosa ajena tiene derecho a conservarla y hacerse pago con su importe; es decir, el derecho real de prenda subsiste con todos sus efec- 
tos. La solución comentada, contenida en el artículo 1000 como se ha dicho, parece contradictoria con la exigencia a que se refiere el inc. 3 del art. 981. de cuya lectura parecería desprenderse que en caso de no ser dueño de la cosa el constituyente de la prenda, ésta sería nula. (12). Sin embargo, la solución es congruente con la tónica del Código en materia de propiedad mobiliaria, contenida en el art. 890 y conforme al cual quien recibe de buena fé y como propietario la posesión de un mueble, adquiere tombién el dominio, aún cuando el enajenante carezca de facultad para hacerlo. Este artículo, aplicable de modo concreto a quien adquiere la propiedad, es $\in$ n verdad el contenido práctico del principio que informa el Código: "en materia de muebles, la posesión equivale al título", y resulta así el fundamento del artículo 1000, materia de examen.

Existe, sin embargo, una pequeña diferencia entre los artículos 890 y 1000 , que consiste en lo siguiente: mientras el artículo 1000 se refiere expresamente al caso de los bienes perdidos, el artículo 890 omite incluirlos en las excepciones contenidas en su segundo párrafo. Esto nos llevaría a la conclusión de que el comprador de buena fe de una cosa perdida no estaría sujeto a la acción reivindicatoria que interpusiera el verdadero dueño; mientras que el acreedor de buena fe que recibió en prenda un objeto perdido, si estaría expuesto a la reivindicación.

La conclusión no parece correcta porque habría disparidad de solución legal en casos iguales, lo cual es inaceptable. Nos inclinamos, en consecuencia, por la siguiente interpretación: dentro de la fórmula genérica de "bienes regidos por'el Código Penal", a que se refiere el artículo 890 , no debe comprenderse solamente los robados sino también los perdidos. Así, las reglas contenidas en los artículos 890 y 1000 se unifican, como en realidad debe ser.

Siempre en esta eventualidad de que se entregue en prenda un bien ajeno, hemos examinado las relaciones entre el acreedor prendario y el verdadero propietario de la cosa. A ellas se refiere el artículo 1000 . Existen, sin embargo, otras relaciones entre el acreedor prendario $\mathrm{v}$ su deudor, derivadas de la entrega hecha por éste de una cosa ajena. Puede ocurrir que el acreedor devuelva la prenda que no es de su deudor. En esta eventualidad, conforme al artículo 992, puede exigir la entrega de otra prenda equivalente.

En caso de que el deudor no entregara otra prenda equivalente, el acreedor puede exigir el cumplimiento de la obligación principal. Así lo dice exprescmente el art. 991 e idéntica disposición tienen otras legislaciones como la chilena y argentina.

d) Para que tenga efectos contra terceros, la prenda debe constar por escrito de fecha cierta. Como hemos indicado anteriormente y como aparece del mismo artículo 983, este requisito del escrito de fecha cierta es únicamente para que la prenda surta efectos frente a terceras personas, es decir aquellos que no son el acreedor y el deudor.

En realidad, la prenda como la hipoteca y en general todos los de.

(12) Con la hipoteca ocurre precisamente de este modo, es decir si el constituyente del gravémen no es verdadero dueño, la hipoteca es nula, inezistente (art. 1013 inc. 1). 
rechos reales, tienen vigencia social. Sus efectos típicos $y$ más saltantes son la persecusión y la preferencia, los cuales se hacen valer contra terceros. En este sentido, resulta difícil distinguir la prenda "sin efectos frente a terceros" de aquella otra que "surte efectos contra terceros". La primera no sería prácticamente prenda por carecer precisamente de los atributos que tipifican al derecho real. En este sentido, el requisito del escrito de fecha cierta, previsto en el artículo 983, resulta prácticamente de la naturaleza de la institución.

Conforme al artículo 986 del Código y de acuerdo con la opinión uniforme de la doctrina, sobre una misma cosa se puede constituir varias prendas. Es decir, el mismo bien puede ser afectado varias veces en garantía del cumplimiento de otras tantas obligaciones. Llegado el caso de incumplimiento y ocurrida la subasta o remate de la cosa, las preferencias se han de regular de acuerdo a las fechas en que fueron constituídas las prendas. Nótese que no se sigue el órden en que se contrajeron las obligaciones principales, sino conforme a las fechas de las prendas. Para este efecto, es decir para poder establecer la prelación, la ley exige el documento escrito de fecha cierta.

El artículo 984 nos dice qué debe contener el documento de la prenda: una referencia a la obligación principal y una designación detallada de los objetos dados en prenda. Lo primero se justifica porque la prenda es necesariamente accesoria de una obligación. Debe, pues, indicarse de qué obligación es ella garantía en cada caso. En cuanto a la relación de los objetos dados en prenda, ello se exige a fin de que conste, a modo de inventario, cuáles son los bienes que el acreedor tendrá que devolver a su deudor una vez que la obligación sea cumplida.

El documento de la prenda debe contener una tercera indicación, que es quizás la más importante: fecha cierta. Debemos entender fecha indubitable. No es dable exigir escritura pública, si bien, claro está, en ella la data consta de modo indiscutido. Podría en consecuencia tratarse de un simple documento privado, siempre que contuviera la indicación inequívoca de la fecha. Se aconseja, a fin de evitar dudas, que el documento privado se otorgue con las firmas legalizadas por Notario Público, diligencia ésta que es necesariamente fechada.

4.-EFECTOS DE LA PRENDA.-Dentro de este tema, debemos examinar: a) derechos del acreedor, b) obligaciones del acreedor $\mathrm{y}$ c) obligaciones eventuales del deudor.

a) Derechos del acreedor.-Son los siguientes: 1) Derecho a retener la prenda, 2) Derecho a hacer vender la prenda y 3) Derecho de preferencia.

1) Derecho a retener la prenda.-Consiste en la facultad que tiene el acreedor de conservar la cosa hasta que se produzca el pago. Algunos tratadistas denominan este derecho como "de retención". Hemos preferido no utilizar este término porque este derecho es de naturaleza diferente al de retención legislado en los artículos 1029 al 1035.

En algunas legislaciones se consignan disposiciones expresas que confieren al acreedor la facultad de conservar la cosa en su poder mien- 
tras la obligación no se cumpla. Nuestro Código ha omitido un artículo de ese tipo. En cambio dispone, en el artículo 993, la obligación que tiene el acreedor o el tercero que tuviera la prenda en su poder, de devolverla al producirse el cumplimiento de la obligación. En definitiva es lo mismo. sólo que la fórmula está consignada en términos de obligación del acreedor $\mathrm{y}$ no de derecho.

¿Cuál es la naturaleza de este derecho del acreedor a retener la prenda? ¿Es un derecho personal que puede oponerse solamente al deu. dor, o es un derecho real que puede invocarse trente $a$ todos? Dicho en otros términos $\mathrm{y}$ suponiendo que la prenda fuera embargada $\mathrm{y}$ rematada por otro acreedor, ¿podría el acreedor pignoraticio oponerse a la entrega de la cosa al comprador? Nuestro Código no resuelve el problema. Sin embargo, la doctrina y algunas legislaciones extranjeras están de acuerdo en que el acreedor no tiene derecho a retener la cosa en la eventualidad referida; lo cual quiere decir que la facultad de que goza el acreedor prendario para retener la cosa es de tipo personal, oponible por consiguiente sólo al deudor. Esto no quiere decir que el derecho de prenda sea también personal. Ya hemos visto que su naturaleza es real, $y$ esto se advierte con claridad si consideramos el derecho preferencial de que goza el acreedor prendario para hacer efectivo su crédito con cargo al precio en que sea vendida la prenda. Por esto se sostiene con énfasis que los derechos reales de garantía -Y entre ellas, la prenda- no recaen en última instancia sobre el bien mismo sino sobre el importe de su realización. Queda así aclarada la naturaleza personal que tiene la facultad de retener la cosa hasta que haya pago - retención que se justifica sólo por razones de publicidad y seguridad- a diferencia del derecho real de que goza el acreedor pignoraticio.

Se plantea una cuestión de difícil solución en caso de que el acreedor prendario pierda la posesión de la cosa, ya sea porque fué despojacio o porque le fué sustraída o la perdió. (No incluímos la posibilidad de que la hubiera devuelto voluntariamente el deudor, porque como hemos visto ello implica la terminación de la prenda por renuncia). En síntesis. se trata de una pérdida de posesión producida involuntariamente. ¿Tendrá derecho el acreedor prendario a perseguir la cosa para subastarla y hacerse pago? ¿Su derecho real es oponible $y$ preferente al de un adquirente a título oneroso $\mathrm{y}$ de buena fe? ¿Qué acción habría de interponer el acreedor despojado contra el actual tenedor? Tratemos de responder estos interrogantes.

Digamos, en primer término, que no hay disposición alguna en nuestro Código, ubicada en el título de la prenda, que resoonda a esta cues. tión. Sin embargo, es preciso tener en cuenta que la doctrina posesoria que informa nuestro Código es la de Ihering, conforme a la cual el elemento "animus" no es exigido, y el "corpus" debe ser entendido como el comportamiento normal y económico del hombre frente a la cosa (variable en cada caso). En estas circunstancias, se admite que la interrupción involuntaria de la posesión, ya sea por despojo o pérdida, no produce necesariamente la extinción de la posesión. Es decir, se puede ser poseedor sin contar con la tenencia física de la cosa. En abono de esta tesis podemos citar los artículos 826 y 875 . Conforme al primero, se conserva la po- 
sesión aunque su ejercicio esté impedido por hechos de naturaleza pasajera; y de acuerdo a este último, la interrupción de la prescripción no se produce en caso de que el poseedor recupere el bien dentro de un año o por sentencia le es restituído.

Conforme a lo expuesto, creemos que en caso de haber pedido la cosa o de que le hubiera sido sustraída, el acreedor prendario tiene derecho a interponer acción judicial persecutoria, lo cual quiere decir que el derecho de prenda subsiste. La demanda sería la de un interdicto de recobrar y el plazo para su interposición sería, conforme a las reglas generales de los interdictos, el de un año. No cabría, desde luego, una acción reivinaicatoria porque ella corresponde únicamente al propietario; y tampoco procedería una acción posesoria ordinaria si es que se planteara después de un año del despojo (art. 875, ya citado).

¿La acción referida podría ser interpuesta solamente contra el que sustrajo la prenda o también contra los adquirientes sucesivos de buena fé y a título de propietarios? Creemos que contra ambos, ya que en aplicación de la segunda parte del artículo 890, estos últimos no estarían amparados (se trataría de bienes regidos por el Código Penal).

2) Derecho de hacer vender la prenda.-En caso de producirse el incumplimiento del deudor, el acreedor puede pedir la venta judicial de la prenda. Asi lo establece el artículo 996.

No nos corresponde examinar la forma en que se procede a la subasta, ya que ello es un problema de procedimiento. Conviene sin embargo dejar establecido que la venta judicial supone una previa tasación por peritos, a fin de acordar conforme a ella la base de la subasta. Recordemos que no es el propósito de la ley privar al deudor a todo trance y como dé lugar del bien de su propiedad sobre el cual recae la prenda. El deudor tiene también derechos y uno de ellos es a que el bien se venda en el precio más justo posible, a fin de reservar para sí el remanente, si es que lo hubiera y una vez hecho efectivo el crédito a su cargo, más intereses y costas.

La disposición contenida en el artículo 996, relativa a la venta judicial de la prenda, es de orden público: como lo son también las reglas del Código de Procedimientos Civiles que se refieren a la forma como debe procederse a dicha venta judicial. De esto se infiere que no puede convenirse un procedimiento que no sea el de la venta judicial: cualquiera convención que al efecto se celebrara sería nula.

A este respecto, debemos referirnos a lo dispuesto en el artículo 1002, según el cual es nulo el pacto por virtud del cual el acreedor se apropia de la prenda por la cantidad prestada, en caso de incumplimiento. (Pacto llamado "comisorio", que mereció prohibición desde el derecho romano a fin de proteger al deudor. Se ha dicho que el objetivo es impedir la explotación de la miseria por la avaricia).

A pesar de que el texto del artículo 1002 no es muy claro, entendemos que comprende las prohibiciones siguientes:

a)-Convenio previo según el cual el acreedor hace suya la prenda, en caso de incumplimiento, por el monto de su crédito (situación ésta explícitamente prevista);

b)-Convenio previo según el cual el acreedor hace suya la prenda, 
en caso de incumplimiento, aún cuando fuera conviniendo el precio de la cosa y compensando el acreedor la diferencia en caso de que la hubiera; c)-Toda clóusula que autorice al acreedor para disponer de la cosa dada en prenda, fuera del modo de la venta judicial prevista en la ley.

De lo anterior parece desprenderse que el acreedor jamás puede llegar a convertirse en propietario de la prenda. Ello no es sin embargo rigurosamente exacto. El acreedor puede llegar a ser dueño de la cosa si interviniera en el remate como postor e hiciera la postura más alta o en caso de que no hubiera postores en el remate (ver, al respecto, el art. 719 del Código de Procedimientos Civiles).

Siempre, sin embargo, será preciso que medie un remate públics, ya que ésta es la única forma de garantizar el derecho del deudor.

3) Derecho de preferencia.-Por ser titular de un derecho real, el acreedor prendario goza del derecho de preferencia. Assí está establecido. de modo expreso, en el artículo 985.

La colisión de créditos puede ser de dos clases: a) entre créditos prendarios $y$ b) entre créditos prendarios $y$ otros que no lo son.

a-Si hay varios créditos prendarios respecto de la misma cosa, la preferencia se regula conforme al artículo 986 en su parte final: deba estarse al orden en que fueron constituídas las prendas.

b-Si hubiera créditos prendarios y otros que no lo son, es preciso establecer cuál es la naturaleza de estos últimos. Si fueran créditos simples, no hay duda que la preferencia corresponde al crédito pignoraticio, aún cuando su fecha de constitución fuera posterior. Pero si se tratara de créditos privilegiados (aquellos que se denominan genéricamente "privilegios", a los cuales nos referimos antes de modo somero), éstos tendrían preferencia, siguiendo a este respecto las reglas contenidas en los artículos 760 del Código de Procedimientos Civiles y 253 y 110 de la Ley Procesal de Quiebras.

Omitimos profundizar en esta materia porque escapa del ámbito de este trabajo.

b) Obligaciones del acreedor.-Son dos, conforme a la ley peruana: 1) Conservación de la prenda, y 2) Responsabilidad por su pérdida o deterioro.

1) Conservación de la prenda.-El artículo 988 establece claramente que el acreedor debe guardar la cosa "como propia". Esto no quiere decir, sin embargo, que goce de las facultades del propietario, sino que debe poner toda la diligencia y atención en el cuidado de la cosa, como lo haría el dueño.

El derecho de guardar la prenda no autoriza al acreedor para usar de ella, salvo que cuente con el consentimiento del deudor. Su posesión es inmediata, lo cual significa que no lo conduce a la prescripción adquisitiva.

2) Responsabilidad por pérdida o deterioro de la prenda.- Tres artículos del Código se refieren a esta materia. Son el 989, el 994 y finalmente el 995. De la lectura de la primera de estas disposiciones, se desprende que el acreedor responde por la pérdida o deterioro sólo en caso de que abuse de ella. Del texto del artículo 994, en cambio, se infiere que el acre- 
edor responde por la pérdida sólo en caso de que ésta se hubiera producido por su culpa. Creemos que de estos artículos, así como del 995, se desprenden las reglas siguientes:

$a-$ No sólo en caso de que el acreedor abuse de la prenda, sino también si la usa sin autorización del dueño, deberá responder de su pérdida o deterioro;

b-Aún cuando el acreedor no hubiera usado ni abusado de la prenda, deberá también responder de su pérdida o deterioro si ellos se produjeron por su culpa (es decir, si hubo negligencia o cualesquiera otra omisiones propias de la culpa, que demuestren que no cuidó el acreedor de la cosa como propia);

C-El artículo 994 establece una presunción "juris tantum" de culpa. Quiere esto decir que en principio el acreedor responde siempre oor la pérdida o deterioro. Para eximirse de la responsabilidad, deberá destruir la presunción $y$ acreditar que no hubo culpa;

d-Si la pérdida o el deterioro ocurren después de cumplida la obligación principal, el acreedor responde si es que no tuvo justa causa para demorar la devolución de la prenda. Queda eximido de esta responsabilidad solamente si prueba que la pérdida o deterioro se habrian producido también de haber estado la cosa en poder de su dueño.

c) Obligaciones del deudor.-Una vez entregada la prenda, esto es constituído el derecho real, el deudor no tiene obligaciones en lo que a la prenda respecta. Eventualmente, sin embargo, pueden ellas surgir. El Código establece dos, que son la de pagar los gastos de conservación de la prenda y la de sustituirla cuando ella es insuficiente.

1) Pago de los gastos de conservación.-Como hemos visto el acreedor debe conservar la cosa como si fuera propia. En esta labor de conservación puede incurrir en gastos, los cuales deben serle reintegrados por el deudor, conforme al artículo 990.

No se establece en nuestra ley si este crédito del acreedor queda cubierto por la garantía prendaria o nó. En otros términos, no se ha resuelto expresamente si el acreedor podría eventualmente pedir el remate de la prenda en caso de que no le reembolsaran las expensas de conservación. Pensamos que sí, por virtud de lo dispuesto en el artículo 1001, referente a la prenda tácita, que veremos después. En otros países, como por ejemplo en Chile, aún cuando no se dice que la garantía prendaria cubre también los gastos de conservación, se establece el derecho de retención en favor del acreedor, quien no está obligado a devolver la cosa mientras dichos gastos no le sean abonados.

2) Sustitución de la prenda - Nos hemos referido en parte a esta obligación cuando tratamos el tema de la constitución de la prenda sobre cosa ajena. Dijimos entonces que si en esta eventualidad el acreedor devolviera la prenda a su verdadero dueño, tiene derecho a que el deudor le entregue otra prenda equivalente (art. 992).

Igual derecho tiene el acreedor en caso de que la prenda resulte insuficiente por causa del deudor o por vicio de la cosa. Supongamos, en vía de ejemplo, que la prenda padeciera de vicio oculto. Es obvio que en 
estas circunstancias la garantía no es suficiente. El deudor estaría obligado a sustituirla. Si no lo hiciera sería de aplicación el art. 991.

Parecería que el artículo 987 estableciera otra eventual obligación a cargo del deudor... Ocurre, sin embargo, que es al revés: se trata de un derecho de que goza el deudor. Si se acreditara judicialmente la necesidad de cambiar la prenda por otra equivalente, dicha sustitución procedería. No ha dicho la ley qué procedimiento habría que seguir en este caso. Nos resistimos a creer que, en aplicación del artículo 296 del Código de Procedimientos Civiles, fuera necesario el trámite ordinario. Nos inclinamos por el procedimiento de necesidad y utilidad para la venta de bienes de menores (arts. 1337 y ss. del C. de P. C.), que sería aplicable por analogía.

5.-EXTINCION DE LA PRENDA.-No existen disposiciones en nuestro Código que de modo expreso se refieren a esta materia, salvo el artículo 993, que establece la obligación que tiene el acreedor de devolver la prenda cuando se cumple la obligación; lo cual, más que una forma de extinción de la prenda, es una consecuencia de ella.

En doctrina se reconocen las siguientes formas de extinción de la prenda, que consideramos con efectos en nuestro derecho.

a) Extinción de la obligación principal.-Esto es consecuencia de que la prenda ez un derecho accesorio. Ya lo comentamos anteriormente y sólo nos queda reiterar que la forma ordinaria como se extingue la obligación es por el pago (cumplimiento, en términos genéricos). Sin embargo, también puede extinguirse la obligación de algún otro de los modos previstos en la ley civil: compensación, transacción, novación, etc., aún cuando en este último caso la extinción de la prenda ocurre solamente si la novación es por cambio de deudor.

b) Confusión. - Puede ocurrir que el acreedor prendario adquiera la propiedad de la cosa empeñada. En esta eventualidad la prenda se extingue, ya que ella debe recaer necesariamente sobre $\cos \alpha$ ajena. Desde luego que en este caso el crédito subsistirá, aún cuando sin la garantía prendaria especifica.

c) Renuncia. - Esta forma de extinción de la prenda admite dos formas: expresa y tácita. Eista última se produce, como ya hemos dicho anteriormente, por el solo hecho de que el acreedor devuelva la prenda a su propietario.

Queda por examinar, en lo que respecta a la extinción de la prenda, lo que ocurre en caso de que prescriba extintivamente el derecho del acreedor a hacer efectivo su crédito. El plazo de prescripción que rige en esta materia es el de la acción personal, es decir 15 años (art. 1168 inc. 2 del C. C.).

Hay tratadistas que se adhieren a la doctrina romana y sostienen que la circunstancia de que el deudor no reclame la devolución de la prenda importa de su parte el reconocimiento tácito del derecho del acreedor $y$. por consiguiente, el plazo de la prescripción habría sido constantemente interrumpido (13).

(13) Así, Salvat, Aubry y Rau, Laurent, Baudry-Lacantinerie, Planiol y Ripert. 
Discrepamos de este parecer. Es evidente que el deudor no puede reclamar a su acreedor la devolución de la prenda mientras la obligación está vigente $\mathrm{y}$ el piazo de la prescripción está corriendo. Su pretensión sería improcadente; y ciertamente el derecho no puede exigir cue se cumpla con un trámite de esta naturaleza a fin de que no se derive un efecto perjudicial. La prescripción extintiva extingue; es decir, hace desaparecer, pone término. Si esto ocurre con el crédito, el cual juridicamente desaparece por virtud de la prescripción, ¿no es evidente que la prenda debe también extinguirse y que, por consiguiente, el acreedor está obligado $\alpha$ devoiveria $\alpha$ su propietario?

Producida la extinción de la prenda, como una consecuencia ineludibie, el acreedor queda obligado a la devolución de la prenda. A este efecto se refiere el artículo 993. Debe devolverse la cosa y además todo cuanto a ella se hubiera adherido (caso de los frutoz).

En caso de que el acreedor no devuelva la cosa una vez extinguida la prenda, es obvio que el deudor debe ejercitar la acción judicial correspondiente. Gozará a este efecto, no sólo de la acción reivindicatoria, en la que necesariamente tendrá que acreditar su condición de propietario; sino también de una acción posesoria ordinaria, innominada en nuestra ley pero que en doctrina se llama "acción pignoraticia directa". En esta segunda eventualidad no será necesario entrar a la prueba de la propiedad. Bastará que el deudor demuestre que hizo entrega de la cosa a título de prenda, que ésta se ha extinguido y que el deudor no ha cumplido con devolveria.

¿Cuál es el plazo para el ejercicio de estas acciones? Antes de responder a esta pregunta es preciso establecer previamente si el acreedor puede prescribir adquisitivamente a su favor. Conforme vimos anteriormente, el acreedor prendario es un poseedor inmediato; por consiguiente, carece de "animus domini", lo cual quiere decir que no posee ad-usucapionem (arts. 894. 871 y 873). Esto ocurre, sin embargo sólo mientras es acreedor prendario. Pero si la prenda se extingue (ya sea por cumplimiento de la obligación o en la forma que fuera), su posesión no es más la de acreedor prendario, ni es tampoco inmediata. Su posesión resultaría entonces "como propietario" y se tornaría ad-usucapionem.

Como consecuencia de lo expuesto, el plazo para el ejercicio do las acciones reivindicatoria y "pignoraticia directa", antes referidas, es ol mismo que el de la prescripción adquisitiva larga, que en materia de bienes muebles es de cuatro años (art. 892). Este plazo se cuenta a partir del momento en que se extinguió la prenda. A su vencimiento, el ex-acreedor prendario adquiere el dominio de la cosa.

6.-PRENDA DE CREDITOS Y ACCIONES. - Anteriormente nos hemos referido someramente a la forma que adopta el desplazamiento o entrega en el caso de derechos. El artículo aplicable es el 982 . Dicha disposición se ocupa de los créditos y de los valores. Sobre esta clase de bienes incorporales pueden constituirse prenda, con la condición de que conste por escrito. Si no fuera así, no cabría entrega y por consiguiente la prenda sería ineficaz.

Cuando se trate de créditos, deberó cumplirse dos requisitos: 1) entrega del título en que consta el crédito y 2) notificación al deudor. Respecto 
a lo primero, debemos entender por "título" el instrumento, ya sea privado - público. La entrega del título al acreedor o a un tercero, tiene por fina. lidad crear, para el deudor que ha constituído la prenda, la imposibilidad material y definitiva de disponer del crédito pignorado. Esta finalidad se cumple mejor en el caso de que el título fuera un documento privado; pero aún en el caso de instrumentos públicos, a pesar de que el deudor podría obtener un segundo testimonio notarial si quisiera hacer efectivo el crédito. ello se torna difícil con la notificación que debe hacerse al deudor del crédito. Esta es, precisamente, la finalidad de esta notificación la cual debe practicarse conforme a lo dispuesto en el art. 1457.

Cuando se trate de valores o acciones, hay que distinguir según sean los certificados nominativos o al portador. Si fueran los primeros, será preciso que el deudor constituyente de la prenda los endose en favor del acreedor pignoraticio. Es evidente que el endoso no debe ser pleno, es decir aquel que transfiere el dominio, sino limitado a la trasmisión de sólo la posesión para los efectos prendarios. Si las acciones fueran al portador, bastaría la simple entrega del título.

El Código contiene tres disposiciones más relativas a la prenda de derechos. Son los artículos 997 a 999, de los cuales se desprenden las roglas siguientes:

a) El acreedor está obligado a cobrar los intereses o dividendos que el crédito o acciones devenguen. Dichos intereses no le corresponden en propiedad porque ellos son frutos y éstos pertenecen al propietario de la cosa.

b) Los intereses o dividendos que el acreedor cobrara, deben ser aplicados al pago de los intereses de la obligación principal $y$, si excedieran, al capital de la misma.

c) El acreedor está obligado a ejercitar las acciones necesarias para que el crédito que le ha sido pignorado no se extinga. En consecuencia, si dicho crédito resultara incobrable, ya sea porque prescribió o porque el cbligado devino insolvente debido a falta de diligencia del acreedor prendario, éste resultará responsable de su importe ante el deudor. $\bar{A}$ este respecto, rigén las normas contenidas en los artículos 989, 994 y 995.

d) Si el crédito pignorado resultara exigible, el acreedor prendario, como consecuencia de la obligación que tiene de accionar, puede resultar cobrando el capital adeudado. En esta eventualidad, la prenda recae sobre este último y queda sometida a las reglas de la prenda de dinero, que veremos a continuación.

Debido a la obligación que tiene el acreedor de aplicar los intereses del crédito pignorado al pago de los intereses y capital adeudados, hay autores que pretenden asimilar esta figura de la prenda de créditos a la anticresis. Expresan que, al igual que en esta última, el acreedor recibe un bien cuyos frutos se aplican a la cancelación del crédito principal. La única diferencia radicaría en la naturaleza de los bienes afectados, muebles en el caso de la prenda, inmuebles tratándose de la anticresis.

Creemos que en verdad la prenda de créditos no constituve una anticresis mobiliaria, ya que en esta última lo esencial es que los frutos del inmueble cancelen la obligación y sus intereses, sin que, en circunstancias 
normales, el deudor tenga que hacer ningún otro desembolso. Quiere esto: decir que el deudor destina un bien de su propiedad $\alpha$ efecto de que con su explotación se haga pago el acreedor. En la prenda de créditos, en cambio, el propósito del deudor es que el crédito o las acciones pignoradas. sirvan solamente de garantía. Por su parte el deudor ha de satisfacer la obligación en los plazos y forma que se convenga. Ahora bien, si entre tonto la prenda produce réditos, lógico es que ellos se apliquen a amortizar la deuda, pero de un modo subsidiario.

7.-PRENDA DE DINERO.-Nuestro Código no contiene disposición alguna respecto de esta prenda. En doctrina, generalmente se le admito (14).

Se podría sostener que como los derechos reales son solamente aquellos que la ley autoriza (ant. 852), no cabría constituir entre nosotros esta. prenda de dinero ya que el Código no la prevee de modo expreso.

En la práctica, sin embargo, la prenda de dinero se utiliza con frecuencia. Se le llama caución, y así se la emplea para ciertos cargos públicos, especialmente cuando se manejan fondos. Igualmente, "la conocida. figura del depósito de garantía en las locaciones, no es en realidad más. que una prenda de dinero" (15).

8.-PRENDA TACITA.-En principio, la prenda existe solamente cuando. se la crea de modo expreso. Sin embargo, como una excepción a esta. regla, el Código nuestro admite la llamada "prenda tácita" en su artículo. 1001. Allí se dice que la prenda que garantiza una deuda sirve de igual garantía $\alpha$ otra que se contraiga entre los mismos acreedor $y$ deudor, siempre que la nueva deuda conste por escrito de fecha cierta.

Esta figura existe desde el derecho romano, y la han recogido la. mayoría de las legislaciones modernas. Sin embargo, en no todas éstas funciona igual, ya que se exigen diferentes requisitos.

Conforme al artículo 1001, materia de examen, para que exista la prenda tócita, se requiere:

1 - que la deuda haya sido contraída con posterioridad a la que está garantizada con prenda. Esto no era así en el derecho romano, con-forme al cual podía ocurrir al revés, esto es que la obligación garantizada. con prenda podía ser posterior, $y$ sin embargo sus efectos alcanzaban también al crédito quirografario anterior:

2 - que la segunda deuda sea contraída "entre los mismos acreedor $y$ deudor". Esto se justifica porque son los mismos acreedor $y$ deudor los que tienen la intención de extender los efectos de la prenda que ya. existe. En consecuencia, no hay lugar a la prenda tácita si la segunda obligación llegase a pertenecer al acreedor por haberla recibido de un tercero (por ejemplo, por subrogación o cesión); $Y$

3 - la nueva deuda debe constar por escrito de fecha cierta. Esta

(14) Isi Pothier. Troplong. Baudry-Lacantinerie.

(15) Castañeda, Jorge Eugenio, "Inetituciones de Derecho Civil". Lima, 1957. 
exigencia se justifica porque sólo asi será posible establecer si se cumple o no con el primer requisito, esto es que la segunda obligación sea pos. terior a la que está garantizada con prenda.

En otras legislaciones, como por ejemplo la argentina y la chilena, se exige también que la segunda obligación resulte exigible antes que la asegurada con prenda. No encontramos justificación alguna a esta exigencia.

En cuanto a los efectos de esta "prenda tácita", nuestro Código no contiene reglas. Otras legislaciones sí se refieren a ello, y hay algunas que dicen que la prenda tácita faculta al acreedor para retener la prenda, pero no le confiere derecho de preferencia. Entendemos que esta interpretación no sería válida entre nosotros, en primer lugar porque a falta de disposición expresa son aplicables a la prenda tácita todas las disposiciones del título, entre ellas las referentes a la preferencia; $y$, en segundo término, porque la exigencia del escrito de fecha cierta tiene precisamente la finalidad de determinar la data de la obligación (y de la prenda también porque ella es automática) para los efectos de la prelación.

\section{S U M A R I O}

\section{LASS GARANTIAS}

\section{LA PRENDA CIVIL}

1.-Noción

2.-Caracteres:
a) Derecho accesorio,
b) Derecho mobiliario.
c) Derecho indivisible,
d) Especialidad de la prenda.

3.-Requisitos:

a) Entrega o desplazamiento de la prenda.

b) La prenda debe asegurar el cumplimiento de una obligación.

c) La prenda debe ser constituída por el propietario de la cosa,

d) Debe constar por escrito de fecha cierta.

4.-Efectos de la prenda:

a) Derechos del acreedor:

1) Derecho a retener la prenda,

2) Derecho $a$ hacer vender la prenda,

3) Derecho de preferencia. 
b) Obligaciones del acreedor:

1) Conservación de la prenda,

2) Responsabilidad por la pérdida o el deterioro de la prenda.

c) Obligaciones del deudor:

1) Pago de los gastos de conservación,

2) Sustitución de la prenda.

5.-Extinción de la prenda:

a) Extinción de la obligación principal,

b) Confusión,

c) Renuncia.

6. - Prenda de créditos y acciones.

7.-Prenda de dinero.

8.-Prenda tácita. 